"Participation", "Error Culture", "Social Climate/Organisational Climate" and "Prevention as an Integral Part of all Tasks". The campaign is scheduled to start in 2017 for duration of 10 years.

\section{THE EFFECTS OF EXERCISE PROGRAMS IN THE REDUCTION OF WORKPLACE INJURIES AMONGST THE STAFFING COHORT OF RESIDENTIAL AGED CARE SERVICES}

${ }^{1}$ Peter Bewert, ${ }^{2}$ Sharon Callister, ${ }^{3}$ Rohan McDonald. ${ }^{1}$ Executive Manager Care Services the Salvation Army Aged Care Plus; ${ }^{2}$ Chief Executive Officer the Salvation Army Aged Care Plus; ${ }^{3}$ Executive Manager Capital Projects, the Salvation Army Aged Care Plus

10.1136/injuryprev-2016-042156.86

Background Staffing wellness and physical capacity to undertake care tasks are essential to ensuring a resident/consumer focussed approach to care delivery. The Salvation Army Aged Care Plus implemented a staff exercise program with the intention of improving workplace culture and wellness amongst our staff. The program involves two streams of the workforce - direct care givers and administration/office based staff.

Description of Problem The workforce in our organisation identified a higher than average injury rate than industry norm. Our staff were experiencing higher injury rates as a result of undertaking manual handling activities. The most common approach is to 'fix the person', a reactive measure applied once an injury has occurred. This is considered a medical management approach whereby the employer reacts to an injury and the treatment required, and then manages the return to work process. An alternative strategy to reduce or prevent work related musculoskeletal pain and disorders may be achieved by increasing an employee's physical capacity through exercise training interventions.

Results The positive effects of the program are a decrease in Lost Time Injury Frequency Rate and a decrease in Injury Notifications of staff resulting from manual handling injuries

Results for staff have shown increase in satisfaction which is directly related to improvements in wellness and increased dexterity. Happy and Healthy staff who sustain less physical injury as a result of manual handling tasks in the aged care work environment result in improved manual handling techniques utilised in physical care for residents. This program has significantly reduced staff injury and resulted in an increased retention of staff and greater continuity of care for residents.

Conclusions The implementation of the program has had a significant effect on qualitative measures such as satisfaction and resulted in measured reduction of lost time injuries and frequency rates. The anecdotal experience indicates the program has been successful in enhancing a safety management approach in a health care environment.

\section{INTER-ORGANISATIONAL COMPLEXITY AND SAFETY CULTURE IN NUCLEAR INDUSTRY PROJECTS}

Nadezhda Gotcheva, Marja Ylönen. VTT Technical Research Centre of Finland Ltd., Finland

\subsection{6/injuryprev-2016-042156.87}

Background Typically, safety culture models aim at grasping a culture of a coherent unit, and it is vague how to apply them in large-scale project networks that consist of multiple varied agents with somewhat conflicting objectives. Recent studies in the nuclear industry identified a set of practical and theoretical challenges for applying the concept of safety culture in a dynamic network of subcontractors involved in the construction of a new nuclear power plant (Macchi et al., 2013; Oedewald and Gotcheva, 2015). The present work focuses on exploring the links between inter-organisational complexity and safety culture with the understanding that projects are complex systems composed of numerous, heterogeneous and interdependent agents.

Methods Complex nuclear industry projects provide a relevant context for studying inter-organisational aspects and their relations to safety culture, since they involve multiple different companies and coordination across organisational boundaries is required to achieve the project objectives safely and efficiently. The method is literature review and case studies carried out in the nuclear industry in Finland.

Results The study results in characterisation of inter-organisational dynamics and sources of complexity in nuclear industry projects, and discusses implications for safety culture. Some key aspects refer to fragmentation due to many different stakeholders with own practices and value frameworks, local interactions between agents from various national cultures and subcultures, uncertainty, increased diversity and interdependency.

Conclusions The study advances the current understanding of inter-organisational complexity and its implications for safety culture in nuclear industry projects.

\section{TEAMING UP FOR SAFETY - USING RISK ASSESSEMENT TOOLS}

Eva Jakobson Vaagland. Norwegian Safety Forum

10.1136/injuryprev-2016-042156.88

Background Public health work in Norway is mainly focused on lifestyle diseases, diabetes and cardiovascular diseases and the prevention of these. Much less interest is put into injury prevention and safety promotion, although life lost due to injuries is a major cause of death up to 45 years of age, and caring for injuries is a costly part of the national health service. We need to increase awareness about the scope of injuries, causes of injuries and the potential for injury prevention and safety promotion.

Objective The objective is saving lives and protecting people from injuries, by spreading information, and inviting groups to take part in risk assessment work. We want to put safety and injury prevention on the radar of organisations, NGOs, institutions, societies, teams, families, neighbours and individuals. By increasing knowledge and awareness we hope to change attitude and practice.

By sharing facts, information and best practice - easily accessible on a website - we want to increase knowledge and give insight about injuries and safety promotion. We will supply tools, checklists and suggestion on how to carry out safety checks in private homes, playgrounds, outdoor areas around elderly centres etc.

The program can be used by Safe Communities to invite new groups to take part in the local safety scheme. But organisations in all parts of Norway will be invited to take part and get involved in local risk assessment. We hope that the project can be a way to promote interest in injury prevention and safety promotion on a community level.

Results The project is developed in 2015 and will be tested by communities and organisations early 2016. The initial phase; dialogue with stakeholders, developing web site, basic information 